Journal of Teacher Education for Sustainability,

vol. 14, no. 2, pp. 168-180

\title{
SUSTAINABLE SCHOOL INDICATORS: APPROACHING THE VISION THROUGH THE SUSTAINABLE SCHOOL AWARD
}

\author{
Dimitrios Kalaitzidis \\ Council for Environmental Education, Greece
}

\begin{abstract}
The Sustainable School Award is a project for schools that aims to integrate a sustainability perspective into all aspects of school life through sustainable school indicators. It complies with the implementation strategy of the International Plan of Action of the Decade for Education for Sustainable Development (2005-2014) and the Strategy of United Nations Economic Commission for Europe (UNECE). In this paper, we present the vision of a sustainable school and an attempt to connect theory and practice of education for sustainable development in order to approach this vision. A brief report on the first year of the implementation of the project in Greece is also presented.
\end{abstract}

Key words: sustainable school indicators, sustainable school, sustainable development

\section{Introduction}

For more than thirty years environmental education (EE) has been the main vehicle for raising the environmental awareness of students and seeking to change their attitudes and behaviours in relation to the environment. The school was one setting for EE, with teachers the main facilitators of attitudes and behaviour change.

A number of authors have reported on the intrinsic and acquired problems of EE in Greece (Flogaitis, 1993, 2006; Kalaitzidis \& Ouzounis, 2000), problems that have prevented it from realising its potential. Greek schools have features that are not consistent with the principles of sustainability (Papadimitriou, 2010), and, in order for the school to be a significant agent in moving society towards sustainability, it has to be the very object of this change (Orr, 1992; Sterling, 2002). The introduction of education for sustainable development (ESD) (Skoullos, 1995; Papadimitriou, 1998; Flogaitis, 2006), which is considered the successor of $\mathrm{EE}$, accentuated this failure due to the higher requirements of this new kind of education (Papadimitriou, 2010).

The theory and practice of ESD suggests that the participation of the whole school community to promote sustainability is necessary and, consequently, it should adopt a whole school approach (Henderson, 2004; Gough, 2005). Many countries have adopted a sustainable school as a policy goal, such as the United Kingdom (Huckle, 2009), Sweden (Green 
School Award), Australia (Henderson, 2004), etc.

The experiments of the 19th and 20th centuries produced progressive schools that had advantages in relation to sustainability, and such schools had some impact on mainstream schools. Progressive schools inspired people of educational vision and included such innovations as the active participation of students in learning process, the cooperative approach to learning, the democratic functioning of the school leadership, etc. The limits of reform were and are, however, shaped by the dominant educational paradigm which reflects prevailing structures of economic and political power.

\section{The sustainable school}

A sustainable school can be viewed as one element of a future utopian sustainable society. The basic idea of a sustainable school is the integration of sustainability in every aspect of school life, namely, the administration, the learning process, management of buildings, transportation to and from school, the school's relationship with the school community (Huckle, 2010). The management of the school reflects and reinforces what students learn in the classrooms through the ways in which it runs the campus (use of energy and water, transport and travel, food, etc.), and learning is further strengthened by the ways in which the school and its students learn alongside local and more distant communities. The active involvement of students and staff in reflecting and acting on sustainability themes creates a sense of responsibility which, in turn, is transferred to the interactions between the school and the wider community (Australian Government, 2009). To facilitate discussion, we can classify the characteristics of sustainable school into three general domains of organisation (Papadimitriou, 2010): the pedagogic (curriculum, school culture, teaching and learning process), social and organisational (organisation, administration, relations with the wider community and other bodies) and the environmental-technical-economic (school environment, buildings and yard).

The sustainable school label covers a range of variants on the light green to dark green spectrum that ranges from conservative (light green) to radical (dark green). At the light green end, the school will be adopting environmentally friendly measures, such as recycling and energy saving (ecological modernisation, faith to solutions deriving from technology, doing more with less) that offer no real challenge to and even support the status quo. At the dark green end, the school will be adopting a holistic approach to sustainability, including challenging the dominant production and consumption patterns, the dominant values of the consumer society, the dominant distribution of power and financial resources, while, at the same time, challenging the dominant schooling values. The dark green approach implies a more thorough reform or radical change of both environmental and social interactions in the school, allowing students and teaches a more democratic process of decision-making. The current United Kingdom government has taken down the webpage that set out the guidance on the previous government's sustainable schools policy. Eco-schools (managed and promoted by the non-governmental organisation (NGO) "Keep Britain Tidy") are now the main vehicle encouraging a more sustainable schooling in the United Kingdom. 


\section{The pedagogical domain}

The sustainable school adopts participatory and student-centred approaches that develop students' skills, abilities and qualities for critical thinking, intercultural understanding and willingness to participate. These are key attributes of active citizenship. Team teaching around issue-based topics is the pedagogy best suited to sustainable schools. Active students' participation in the planning of the lesson, the teacher's function as coordinator of the discovery of new knowledge by the students themselves, the introduction of new technological innovations in the learning process are all aspects of sustainable school, which relate to improving the conditions of the learning process, while improving the overall functioning of the school. Principles of EE and ESD should be integrated into all aspects of the curriculum (United Nations Economic Commission for Europe [UNECE], 2005). The hidden curriculum teaches students much about sustainability through the day-to-day relations between people and between people, energy, materials and plants/animals on the school campus.

\section{The social and organisational domain}

The social and organisational domain includes the school relations with the local community, local government, relations with parents, etc. The administration must put sustainability at the heart of school design and everyday practice. The sustainable school adopts the democratic and participatory process of decision-making. A proper atmosphere of cooperation should be established so that the school generates improvement plans and undertakes the relevant actions to implement the plans and achieve the goals. The democratic operation, from the administration to the function of student councils, best fits the sustainable school. The decisions taken with democratic procedures are respected by all members of the school community. Local government has an important role in school life as it distributes the annual grant and is responsible for repairs and improvements of school buildings, taking advantage of school programmes to educate and enlighten local citizens, etc. But even more important is the democratic functioning of the teachers' assembly (staff meeting) in each school as its decisions largely determine the nature of school life.

\section{The environmental domain}

The main objective of the Sustainable School Award (SSA) in the environmental domain is to reduce the ecological footprint (Wackernagel \& Rees, 1996) of the school and, through the students, of the families. At the same time, in an era of financial crisis, reducing the ecological footprint will result in reduced spending for running the school building. According to surveys (Santamouris, 2008), 30\% of the energy consumption goes to buildings in Greece. The Greek school buildings are very costly in terms of heating, because none of them was built according to the principles of green building. Besides heating, paper consumption is also booming. Only an insignificant percentage of the paper consumed at school ends up in paper recycling. The contribution of schools to increase greenhouse gas emissions could also 
include the consumption of fuel to transport children to school in their parents' car.

For all these reasons, schools are organisations which produce waste and consume significant quantities of resources, contributing to global warming. The impact of the school is not confined within the narrow limits of its campus, but extends to the broader social environment and affects a substantial part of society.

\section{The SSA}

In Greece, thousands of schools implement optional school projects, short- and mediumterm, and every year. The topics of these projects are about environment, sustainable development, human health, jobs, culture and civilisation, intercultural issues, human or animal rights, theatre, consumerism, etc. The quality of the projects sometimes is high and deserves to be recognised. However, most of them are implemented in isolation, detached from the school community and restricted within the limits of a class. Teachers and students need to be supported and motivated in different ways in order to improve the quality of the projects, prolong their duration for the profit of both the students and the local society and infuse the school community with the principles of sustainability. Introducing incentives for more active student participation in the common effort can often improve the significant achievements of these optional projects.

World conference "Education for Sustainable Development" (United Nations Educational, Scientific and Cultural Organisation [UNESCO], 2009) urges all states to reorient education towards sustainability, to benefit the organisations of civil society in order to encourage debate on education for sustainable development and to undertake initiatives. These positions agree also with the Article 36 of the Strategy (UNECE, 2005), according to which NGOs are important sources of informal and non-formal learning, able to implement processes of social empowerment and to integrate and transform the scientific knowledge and facts into understandable information. Their role as intermediaries between governments and the public should be recognised, promoted and strengthened.

In response to the above, the SSA was established by the Council for Environmental Education of the Hellenic Society for the Environment and Culture in order to recognise, promote and enhance the efforts made by schools in different thematic areas but within the broader context of the ESD. The SSA was also instituted to disseminate good practice sustainability in schools.

The SSA is a project for schools in the form of a contest. The object is for schools to integrate sustainability in all their functions and in particular in the three domains mentioned above, namely: the educational, social-organisational and environmental. The school that decides to participate in the SSA has to visit the website www.aeiforosxoleio.gr to subscribe. Following the subscription, the school undertakes the activities implied by the sustainable school indicators. At the end of the school year, the school inserts the value of each indicator on the website in order to receive its score. 


\section{Sustainable school indicators}

For each one of the above-mentioned domains the Council for Environmental Education has introduced indicators (quality criteria) which facilitate comparisons among the schools participating in the project. Indicators are becoming one of the most commonly applied and promoted evaluation strategies in sustainable development and ESD (Reid, Nikel, \& Scott, 2006). The SSA indicators are based to an extent on the set of sustainable development indicators of UNESCO (UNESCO, 1997; Breiting, Mayer, \& Mogensen, 2005) and have taken into account the indicators for education for sustainable development developed by UNECE - UNESCO (UNECE - UNESCO, 2007; UNECE, 2009). Similar approaches are suggested by UNESCO (UNESCO, 2010) and by the Department of Environment and Heritage (Australian Government, 2005). It encourages schools to undertake an audit to identify areas for improvement in key areas of ESD. This can help schools set targets for change and improvement. As Mogensen and Schnack (2010) state, indicators cannot be seen as a mechanism that aims to prescribe and test the 'correct' content (knowledge, skills and values) in ESD but rather must be formed in ways that stimulate and qualify students to become future citizens, who can make sound judgments, think critically and independently and who can and will play an active role. The same authors state that quality criteria (or indicators) are considered starting points for reflection. The literature may indicate a variety of indicators (Australian Government, 2005, 2009; Morgensen \& Mayer 2005; Department for Education and Skill [DfES], 2007) that all can come under the three domains mentioned above. The difference is that the SSA has introduced in Greece a set of sustainable school indicators that are measurable, so they constitute a new approach to the idea of sustainable school. The full list of the sustainable school indicators is provided in Appendix 1. Each indicator receives a value, including a maximum score that summed up with the rest of the indicators to give the overall score of the school. The scoring of the indicators is designed to give greater or lesser weight to some of them. For instance, it gives less weight to the existence of solar panels on the roof of the school and greater weight the reduction of electricity consumption. The SSA accepts as candidates all types of schools: nursery schools, primary and secondary schools, vocational schools, special schools. Each school competes with the schools of the same category (nursery, primary, secondary, vocational). Each indicator implies an action taken by the school in the direction of sustainability. For instance, the indicator Total number of teaching hours per subject, employing teamwork teaching approaches implies an effort by all the school community to increase the incorporation of teamwork teaching in the teaching strategies of the school. The indicator Number of social and pro-environmental actions of school (planting trees, participating in social fundraising, taking care of animals, etc.) implies that the school will undertake initiatives to contribute to the improvement of the local environment and local society, through different actions and activities. The indicator Does the school have composting systems? implies that the school will start a composting program, etc. 


\section{Results of a questionnaire survey}

The SSA was introduced in Greece for the first time during the school year 2010/2011. 140 schools across the country declared participation in the project-contest. Of these 22 senior high schools, 51 were high schools, 54 primary schools, 10 kindergartens and special schools. After the conclusion of the first year of the project, the participating schools were asked to fill in a special questionnaire (Appendix 2) different from the indicator one (Appendix 1). The questionnaire was completed by teachers and principals of participating schools. Only 35 schools out of the 140 that declared participation in the SSA returned a completed questionnaire (25\%). This negative attitude towards evaluation is a persistent feature of most EE projects and programmes (Morgensen \& Mayer, 2005). Some possible reasons for the low response of schools could be numerous: a fear for evaluation as this is not a common practice in Greek schools (abandoned already from the early 80s); a negative attitude towards behaviourist approaches to education; lack of interesting and meaningful activities at school in the framework of the SSA. A review of similar programmes around the world reveals a lack of research and evaluations reflecting upon the achievements, lessons learnt and critical success factors of whole school sustainability programmes, such as Eco-Schools, Green School Award, Enviroschools (Henderson, 2004). This process would enable programmes to capture both quantitative and qualitative data in order to reflect upon progress, learn from experience and ways to improve (Bolstad, 2004).

The questionnaire sought information about (mainly) improvements in the hidden curriculum, after the implementation of the sustainable school program and participation in the corresponding contest (Appendix 2). Because it was the first year of the implementation of the SSA, there were no comparative data from previous years to depict improvements in school life. The questionnaire asked for estimations from the participating school principals and teachers. Under these circumstances, the results of the survey should be treated with care. Mostly they indicate some attitudes, they do not depict with accuracy and validity all the potential opinions and attitudes. The findings of this survey are numerous.

- The initiative for the school to participate in the SSA derived mainly from the principal.

- The school activities related to the SSA begin mainly in October and end in middle May.

- In most of the participating schools, environmental education projects were implemented as a result of participation in the SSA.

- All schools that responded to the questionnaire have formed students' environmental teams, mainly on a class base.

- Most of teachers said they would participate in the project in the next year, and nobody expressed a negative intent.

- All the teachers said that they will continue the good practices developed within the SSA project whether it would continue or not.

- All schools developed collaboration with NGOs. 
- All schools said to participate in activities in the local society (fundraisers, care of stray animals, etc.).

- Most of schools responded that they have developed relationships with schools in other countries within European Union programs (Comenius, e-Twinning, etc.).

- Most of the teachers said there were positive changes to the hidden curriculum as a result of the participation in the contest.

- The rate of teachers' participation in the different activities implied by the indicators was very high. Similar or even higher rates are claimed for student participation.

- The most active students' teams are recycling, reduction in electricity and water consumption teams.

- The less active students' teams are those that dealt with issues related to the educational sector (introduction of ICT, teamwork approaches to teaching).

- A major change considered by teachers as a result of the participation in the SSA is a significant change in the school climate. Students' and teachers' participation in the design and implementation of different activities in and out of school has led to the development of better relationships of trust and cooperation both between students and between students and teachers. This effect is depicted in the reduced number of punishments and penalties imposed to students.

- Teachers reported as difficulties the limited spare time for secondary school students, the relative difficulty of coordination when teams are mixed, the need for more and a closer contact between coordinators of the SSA and schools, the lack of adequate teacher training, the complexity of some indicators, etc.

\section{Innovation}

A significant change occurs in schools participating in the SSA project as they redirect their work towards sustainability and overall greening. There are numerous innovative elements of the SSA.

- Most of sustainable school indicators are original.

- Measurable indicators for sustainable school are used for the first time to assess effort and achievements of schools in the area of sustainability. No references were found in the relevant literature about appointing a certain value for the fulfilment of a target in the form of an indicator.

- It is the first time that a "whole school approach" (Kalaitzidis, 2001, p. 18) is implemented in large scale and with such positive results in Greece.

- High percentage of participation of both teachers and students is observed. According to estimates, the average rates of participation of teachers and students in medium- and long-term school projects in Greece does not exceed 12\%.

- The SSA integrates various innovative actions taken in one school under the umbrella of sustainability. Thus, the final effect achieved is greater than the sum of 
the individual achievements of the teams participating in each individual action or project.

- In the framework of the SSA, the existing experience and knowledge inherent in schools by former environmental and other projects is reclaimed giving them new content as determined by the active and wide participation of the school community.

- Teachers claim that the SSA has reinforced at a high level the hidden curriculum and improved the school climate.

- The SSA had a catalytic effect on student-school relationships, as evidenced by the rapidly evolving reduced punishments imposed on students.

- The specific and crucial role of school director who encouraged the school to participate in the SSA was confirmed.

- The SSA allowed a big part the members and stakeholders of the school community to take ownership of the initiatives and incentives to participate in the innovation while promoting the development of their environmental consciousness.

\section{Conclusions}

The SSA is a project in the form of a school contest. It is running under the auspices of the Ministry of Education. It puts forward 40 indicators in order to help schools guide themselves towards sustainability. The indicators are original and have been formed taking in account recognised indicators about sustainable development and indicators about Education for Sustainable Development. They cover the three domains of school function: pedagogical, social and environmental. During the first year of the project, 140 schools took part, while in the second year, the number increased to 180 schools. The project is facilitated by a special website (www.aeiforosxoleio.gr) where the participating schools insert the values of each indicator to receive their score. An evaluation questionnaire for the first year showed optimistic results about the effort towards sustainability through the SSA.

\section{Acknowledgement:}

The author would like to express deep thanks to John Huckle for his support in writing this article.

\section{References:}

Australian Government. (2005). Educating for a sustainable future: A national environmental education statement for Australian schools. Retrieved October 10, 2009, from http://www. environment.gov.au/education/publications/sustainable-future.html

Department of the Environment and Heritage. (2005). Educating for a Sustainable Future: A National Environmental Education Statement for Australian Schools. Retrieved October 10, 2009, from http://www.environment.gov.au/education/publications/sustainable-future. 
html

Australian Government. (2009). Living sustainably: The Australian government's national action plan for education for sustainability. Retrieved October 15, 2012, from http://www. environment.gov.au/education/nap/

Bolstad, R., Baker, R., Barker, M., \& Keown, P. (2004). Environment education in New Zealand schools: Research into current practice and future possibilities. Volume 2: A review of national and international research literature on environmental education practices. Wellington: Ministry of Education.

Breiting, S., Mayer, M., \& Mogensen, F. (2005). Quality criteria for ESD schools. Guidelines to enhance the quality of Education for Sustainable Development. Vienna: Austrian Federal Ministry of Education, Science and Culture, Department of Environmental Educatioen Affairs.

DfES (Department for Education and Skills). (2007). Sustainable schools for pupils, community and the environment. Retrieved September 15, 2012, from http://www.dfes.gov.uk/DfES

Flogaitis, E. (1993). Environmental education. Athens. Greek University Press.

Flogaitis, E. (2006). Education for the environment and sustainability. Athens: Ellinika Grammata Publications.

Gough,A.(2005).SustainableSchools:Renovatingeducationalprocesses. AppliedEnvironmental Education and Communication, 4, 339-351. DOI: 10.1080/15330150500302205.

Henderson, K., \& Tilbury, D. (2004). Whole-school approaches to sustainability: An international review of whole-school sustainability programs. Retrieved, September 16, 2012, from http:// aries.mq.edu.au/projects/whole_school/files/international_review.pdf

Huckle, J. (2009). Sustainable schools: Responding to new challenges and opportunities. Geography, 94(1), 13-21.

Huckle, J. (2010). Sustainable schools: Exploring the contradictions. Conference proceedings: 4th National Symposium The Sustainable School of the Present and the Future Athens 2224 January 2010. Athens, Greece: Hellenic Association for the Environment and Culture.

Kalaitzidis, D., \& Ouzounis, C. (2000). Environmental education: Theory and practice. Xanthi: Spanidis.

Kalaitzidis, D. (2001). The whole school approach to environmental education - a test in Ralleios high school for girls of Piraeus. For the Environmental Education, 22, 18-21.

Mogensen, F., \& Mayer, M. (2005). Trends and divergences in the national reports - a comparative analysis. In F. Morgessen \& M. Mayer (Eds.), ECO-schools: Trends and divergences. A comparative study on ECO-school development processes in 13 countries (pp. 52-68). Vienna: Austrian Federal Ministry of Education, Science and Culture, ENSI SEED.

Mogensen, F., \& Schnack, K. (2010). The action competence approach and the new discourses 
of education for sustainable development: Competence and quality criteria. Environmental Education Research, 16(1), 59-74.

Orr, D. (1992). Ecological literacy: Education and the transition to a postmodern world. Albany: SUNY Press.

Papadimitriou, B. (1998). Environmental education and school. Athens: Dardanos.

Papadimitriou, V. (2010). School culture, school climate and sustainable school. Magazine for the Environmental Education, 44, 12-13.

Reid, A., Nikel, J., \& Scott, W. A. H. (2006). Indicators for education for sustainable development: A report on perspectives, challenges and progress. London: Anglo-German Foundation.

Santamouris, M. (2008). Buildings and environment: A burdened relationship in "Fragile Earth". Athens: Elliniki Etairia.

Skoullos, M. (1995). Re-orienting environmental education for sustainable development. Summary report of the inter-regional workshop. Athens: University of Athens.

Sterling, S. (2002). Sustainable education. Schumacher Briefings No. 6. Bristol: Green.

UNECE (United Nations Economic Commission for Europe). (2005). UNECE strategy for education for sustainable development, Vilnius (Agenda points 5 and 6). Vilnius: UNESCO.

UNECE (United Nations Economic Commission for Europe). (2009). Guidance for reporting on the implementation of the strategy on ESD, part III, indicators. In Learning from each other. The UNECE strategy for Education for Sustainable Development. New York and Geneva. UNITED NATIONS. Retrieved September 20, 2012, from http://www.unece.org/ fileadmin/DAM/env/esd/Implementation/Publication/Learning FromEachOther.pdf

UNECE - UNESCO (United Nations Economic Commission for Europe - United Nations Educational, Scientific and Cultural Organisation). (2007). Good practices in education for sustainable development, Sweden Sustainable School Award. Retrieved November 10, 2009, from http://www.unece.org/env/esd/welcome.htm

UNESCO (United Nations Educational, Scientific and Cultural Organisation). (1997). Teaching and learning for a sustainable future. Retrieved October 10, 2011, from http://www.unesco. org/education/tlsf/

UNESCO (United Nations Educational, Scientific and Cultural Organisation). (2005). Draft international implementation scheme for ESD. 172 EX/11. Retrieved October 10, 2009, from http://unesdoc.unesco.org/images/0014/001486/148654e.pdf

UNESCO (United Nations Educational, Scientific and Cultural Organisation). (2009). The Bonn declaration. UNESCO World conference on Education for Sustainable Development. P.4. Retrieved October, 10, 2009, from http://www.unesco.org/education/tlsf/

UNESCO (United Nations Educational, Scientific and Cultural Organisation). (2010). Education for sustainable development lens: A policy and practice review tool education for sustainable development in action learning \& training tools No. 2. Retrieved October 15, 
2012, from http://unesdoc.unesco.org/images/0019/001908/190898e.pdf

Wackernagel, M., \& Rees, W. (1996). Our ecological footprint: Reducing human impact on the earth. Gabriola Island, British Columbia: New Society Publishers.

\section{Appendix 1}

\section{Sustainable school indicators}

\section{A. Pedagogical indicators}

1. Incorporation of sustainability issues in school subjects (health education, different cultures, gender card, human rights, cultural heritage, etc.) per cent (\%).

2. Total number of teaching hours per subject, employing teamwork teaching approaches per cent (\%).

3. Incorporation of ICT for teaching of all subjects used to develop cooperation skills, critical and creative thinking to solve problematic situations.

4. Number of educational visits in order to improve the environmental, social and cultural awareness of students.

5. Number of events (cultural, environmental, etc.) for students, parents or local community members organised by the school in collaboration with students and teachers.

6. Number of optional school activities and projects (Environmental, Health Education, Cultural Education, Comenius, e-Twining, pupil competitions, etc.) implemented in school.

7. Number of punishments imposed to students.

8. Percentage of dropouts.

\section{B. Social and organisational indicators}

1. Does the school implement a Sustainable Management Plan (SMP) and an Activity Programme (SAP)?

2. Part of the total number of school teachers (\%) who are actively involved in SMP.

3. Percentage of students who are actively involved in the SMP.

4. Total hours of professional development seminars attended by school teachers.

5. Total hours of professional development seminars attended by the school principal.

6. Number of teacher meetings (other than mandatory) on teaching and learning approaches to plan joint projects related to education for sustainability, to develop strategies, to link the school with the local and international community, to reflect on the school accomplishments, etc.

7. Number of pupil-council meetings on issues relating to environmental manage- 
ment of the school, teaching methods, safety issues, etc.

8. Number of pupil-general assemblies with the same topics as above.

9. Has the school undergone an aesthetic improvement by students in collaboration with teachers, parents, municipality, etc.?

10. Number of School Councils convened in order to inform the school community, to reflect on school issues (teaching methods, environmental management, etc.).

11. Number of social and pro-environmental actions of school (planting trees, participating in social fundraising, taking care of animals, etc.).

12. Number of lectures on sustainability issues given by out of school specialists who visited the school.

13. Number of collaboration meetings with the local school activities adviser-consultant.

14. Members of the Parents' Association who voted in the last election (\%).

15. Number of visits to the website of the school during the school year.

16. Does the school canteen offer organic food to students?

\section{Environmental-economic-technical indicators}

1. Percentage of students going to school on public transportation, bike/private car/ feet.

2. Weight of recyclable materials (paper, glass, metal and plastic) that were recovered per pupil and teacher.

3. Weight of waste going to landfill per pupil and teacher.

4. Number of copier paper sheets per student and teacher.

5. Water consumption per pupil and teacher.

6. Does the school employ a system for storage and use of rainwater?

7. Electricity consumption per pupil and teacher.

8. Does the school use environment-friendly detergents for cleaning?

9. Weigh electric-electronic devices and batteries given for recycling per pupil and teacher.

10. Is the central heating system checked annually for compliance with Eco Audit?

11. Consumption of oil or natural gas for heating per pupil and teacher.

12. Is the school building insulated?

13. Power of photovoltaic systems installed in school.

14. Does the school run a vegetable garden, flower garden or a roof garden?

15. Number of plants and trees across the surface of the school (courtyard included).

16. Does the school have composting systems? 


\section{Appendix 2}

\section{Questionnaire}

1. Who has taken the initiative to suggest the Sustainable School Award to the school?

2. When did the school start the SSA activities?

3. How many students' teams for implementation of environmental education, health education at school have you organised?

4. Were these teams mixed or pure classes?

5. What percentage of the students did not participate in any activity?

6. What percentage of the teachers did not participate in any activity?

7. What were the most active pupil teams?

8. What were the less active pupil teams?

9. What factors influenced the success of the active pupil teams?

10. What factors influence the relative failure of the less active teams?

11. What major changes have taken place at your school in the framework of SSA?

12. What minor changes have taken place at your school, in the framework of SSA?

13. What were the most serious problems you have faced during the implementation of the project?

14. What were your school accomplishments attributed to the SSA?

15. Are you going to participate next year?

16. If there are no more SSA, are you going to continue the good practices that you have developed during the SSA?

17. What changes do you suggest for the SSA?

18. Do you have any cooperation with NGOs or other bodies?

19. Do you participate in the social activities on local scale?

20. Do you have relations with foreign schools? If yes, in what framework?

21. Have you observed changes in the hidden curriculum of your school as a result of your participation in the SSA?

22. If yes, how can you describe this change?

\section{Correspondence:}

Dr Dimitrios Kalaitzidis. Council for Environmental Education, Elliniki Etairia. Tripodon 28. 10558 Athens, Greece. Tel.: 0030210 4117027. Email: aeiforo@gmail.com 